\title{
School learning support for teacher technology integration from a self-determination theory perspective
}

\author{
Thomas K.F. Chiu ${ }^{1}$
}

Accepted: 3 February 2022 / Published online: 23 February 2022

(c) Association for Educational Communications and Technology 2022

\begin{abstract}
Teacher technology integration research on persistence is needed. Teachers' persistence is strongly associated with their autonomous motivation, as defined by self-determination theory (SDT); however, most SDT-based studies have focused on teachers' support and students' motivation and well-being. SDT founders also recently suggested that future studies should include teacher motivation towards the use of technology. Accordingly, this experimental and longitudinal study aimed to investigate how the proposed support encouraged and sustained the low- and high- quality teachers' integration practices. It proposed a school learning support intervention with three dimensions-leader, expert, and peer support - to meet teachers' basic needs and thereby increase their motivation for and persistence in classroom technology integration. It had a sequential explanatory mixed-methods design, involved 122 school teachers and lasted for 22 months. Pre-, postand delay- questionnaires and two arounds of interviews were used to collect the teachers perceptions on needs satisfaction and technology integration practices. The results suggest that the support increased the extent to which the teachers' needs were met, resulting in more high-quality (student-centered) but not low-quality (lecturing) integration practices. However, the intervention sustained both types of integration practices. The findings offer three major empirical implications, makes two theoretical contributions, and offers four practical suggestions for researchers and practitioners.
\end{abstract}

Keywords Technology Integration - Teacher Education - Self-determination theory · Needs satisfaction · Persistence

Educational technology, a necessary tool in modern classrooms, can provide invaluable support for the learning process by engaging students in interactive learning activities. The quality of technology integration determines how interactive lessons are. Teachers' technol-

Thomas K.F. Chiu

Thomas.kf.chiu@gmail.com; tchiu@cuhk.edu.hk

1 Department of Curriculum and Instruction, Faculty of Education, Centre for Learning Sciences and Technologies, The Chinese University of Hong Kong, Shatin, Hong Kong 
ogy integration practices can be categorized as either low-quality (e.g., direct instruction) or high-quality (fostering self-directed and student-centered learning) (Cheng et al., 2020; Mueller et al., 2008). In the last 30 years, technology integration has drawn widespread attention from educators and researchers (Nelson et al., 2019; Lowther et al., 2008), and its importance has been reinforced by schools' and teachers' experiences of remote learning during the COVID-19 pandemic. Most discussions of the impact of the pandemic on school education have highlighted the importance of teacher technology integration, particularly high-quality practices (Chiu, 2022).

Researchers have proposed various strategies for the adoption of new technology in education based on various factors that influence the technology integration process, such as teachers' attitudes, beliefs, anxiety, technical training, and resources (Cheng et al., 2020; Chiu, 2017; Chiu \& Churchill, 2016; Nelson et al., 2019). Teachers who perceive technology to be valuable to the teaching/learning process are more likely to effectively integrate technology into their classrooms, and teachers who receive more resources from their schools are more likely to use technology to support student-centered learning. Most related studies have used modeling approaches to predict teachers' behavioral intention to adopt technology for their teaching and learning. Teachers' acceptance and adoption of technological innovation are extremely important to the success of technology integration in its early stages. However, authentic and meaningful integration requires not only adoption but also persistence. Such integration practices are strongly associated with teachers' autonomous motivation, which is thus key to the successful integration of technology in classrooms (Ryan \& Deci, 2020). This motivation can be explained by self-determination theory (SDT), which was developed by Deci \& Ryan (1985).

SDT outlines intrinsic and varied extrinsic sources of motivation and explains the dynamics of human need within a social context. It suggests that people can become selfdetermined when their three basic psychological needs - for autonomy (e.g., freedom), competence (e.g., confidence), and relatedness (e.g., connection) — are fulfilled. SDT research has shown that top stakeholders in education, such as administrators and policy makers, can influence teacher motivation and well-being (Chiu et al., 2021; Lee et al., 2020; Nie et al., 2015; Richardson \& Watt, 2018). Therefore, school learning support (e.g., professional development activities) is crucial to promote teachers' technology integration practices. Recently, the founders of SDT called for more studies of teachers' motivations to continue training and achieve instructional goals (Ryan \& Deci, 2020), particularly in technology integration.

Accordingly, this study developed a school learning support intervention with three dimensions - leader, expert, and peer support - to satisfy teachers' basic needs for autonomy, competence, and relatedness and thereby promote their integration of technology in their classrooms. It examined the extent to which the proposed needs-based support met teachers' needs and increased their motivation for and persistence in technology integration. 


\section{Literature review}

\section{Teacher technology integration}

"Teacher technology integration" refers to teachers' use of technology in classrooms to support learning and teaching (Inan \& Lowther, 2010). Its quality is determined by the extent to which teachers use technology for student-centered learning and to personalize student learning (Cheng et al., 2020; Hsu, 2016). Teachers may implement either low- or high-quality technology integration practices (Cheng et al., 2020; Mueller et al., 2008), which can be described in terms of a seven-level (lower levels are low-quality; higher level are high-quality) of technology implementation suggested by Moersch (1995), one of the first researchers to measure classroom technology use. Low-quality integrators use technology to prepare lessons, create and deliver instructional materials (e.g., slides, worksheets, and videos), collect student views, and grade student work. Teachers have often found low-quality practices to be effective and efficient because they save time and costs (Cheng et al., 2020). Highquality integrators use technology to support student-centered and self-directed tasks and to promote adaptive learning. They engage students as active participants in a student-centered learning environment, empowering them to determine when, where, and how learning takes place (Lee \& Hannafin, 2016). If effective, the low- and high-quality integration of technology can positively change the classroom landscape and support teachers.

Teacher technology integration research has identified several factors affecting the success of integration, which can be categorized as external or internal to teachers (Cheng et al., 2020; Ertmer, 1999; Hur et al., 2016). External factors include technical support, principal support, administrative support, pedagogical support, and the availability of digital learning resources (Chiu, 2017; Cheng et al., 2020). Internal factors include teacher beliefs about and interest in teaching with technology, as well as teacher anxiety about new educational technology (Chiu \& Churchill, 2016; Hsu, 2016). These factors have different effects on low- and high-quality integration practices. Chiu (2017) studied 306 middle and high school teachers and suggested that school support is a strong predictor of the use of electronic textbooks (i.e., reading and presenting) in classrooms (low-quality), because this technology is used daily and thereby teachers experience more problems and issues. Hsu (2016) used a mixed-methods approach to collect the views of kindergarten and primary school teachers and found that teachers with constructivist pedagogical beliefs about technology (perceiving learning as an active process of knowledge construction and reconstruction and teaching as a process of facilitating learners' knowledge construction) tended to use technology to support instructional methods promoting higher-order thinking (high-quality integration). Cheng and colleagues (2020) suggested that teacher expectancy (how effectively teachers expect to be able to integrate technology in their classrooms) is a stronger predictor of high-quality integration practices than of low-quality integration practices. These findings provide important guidance for predicting teacher motivation to implement different technology integration practices. External factors promoting teacher technology integration can be considered extrinsic motivators, and internal factors can be considered intrinsic motivators. SDT can explain these two types of factors, as it is a broad framework for understanding factors that promote or undermine intrinsic and autonomous extrinsic motivation (Ryan \& Deci, 2020). 


\section{Self-determination theory and support for technology integration}

SDT (Deci \& Ryan, 1985), a meta-theory for framing motivational studies, outlines intrinsic and varied extrinsic sources of motivation and differentiates autonomous from controlled motivation. An autonomously motivated individual may feel self-directed and self-determined, whereas an individual with controlled motivation may feel under pressure and lack autonomy. The theory considers the inherent human tendency to pursue well-being and growth within a sociocultural context, and it suggests that all individuals have three basic psychological needs - for autonomy (feeling endorsed and self-governed, and ownership), competence (feeling capable and proficient), and relatedness (feeling connected and interacted) - that motivate them to act. Conditions supporting an individual's autonomy, competence, and relatedness can foster high-quality forms of motivation (autonomous motivation) and engagement in activities. Conversely, unmet psychological needs are likely to be detrimental to well-being and growth. Individuals show greater persistence and perform better when these needs are met and can feel isolated, helpless, and unqualified when they are not met (Ryan \& Deci, 2020).

SDT has been widely applied in various educational settings - both in physical classrooms and online, and from K-12 to higher education. Studies in this area have focused on student motivation and well-being (Chiu, 2021a, b, 2022; Ryan \& Deci, 2020) called on SDT researchers to extend their focus to teacher motivation and school leadership. Recent SDT studies have revealed important links between teacher motivation and wellness and school leadership. They have sought to understand how top stakeholders (e.g., administrators and policy makers) and bottom stakeholders (e.g., students and parents) influence teacher motivation and well-being (Lee et al., 2020; Nie et al., 2015; Richardson \& Watt, 2018). These imply that we need more studies of teachers' motivations to continue training and pursue instructional goals (e.g., Chiu 2017; Jang, 2019; Jansen in de Wal et al., 2014; Gorozidis \& Papaioannou 2014; Ryan \& Deci, 2020).

When schools adequately support teachers and fulfill their three SDT needs, teachers show greater commitment to their schools, acceptance of their schools' goals and values, willingness to respond to new challenges, and effort to fulfill their work roles (Heck \& Hallinger, 2014; Lee \& Nie, 2014; Lee et al., 2020). SDT can thus explain the effects of needsbased support on teacher motivation and persistence in relation to technology integration. It can also explain the operation of the internal and external factors identified in teacher technology integration research (e.g., teacher beliefs and values, technical support, principal support). For example, teachers' perceptions of the usefulness of technology are associated with their perceived autonomy, competence, and relatedness (Fathali \& Okada, 2018). Teachers will choose a technology that they find effective and useful for teaching when given options (autonomy). One of the prerequisites for usefulness is teachers' ability to use the technology (competence), and teachers' favorite technology (relatedness) is often the technology that they can use most effectively. Moreover, perceived ease of use is explained by competence (Fathali \& Okada, 2018; Chiu, 2017). Teachers who can apply their computer skills to a wider range of tasks are more likely to use technology because it requires less effort. Thus, the value of technology to student-centered learning depends on teachers' autonomy and competence (Teo et al., 2009). Teachers value technology more when they have the freedom and knowledge required to design their own instruction to foster studentdirected learning. In sum, satisfying the three SDT needs can affect how teachers integrate 
technology in their classrooms. Pedagogical support can enhance teachers' self-efficacy and peer support can influence what teachers value.

In the pedagogical context, the three SDT needs are influenced by various contextual factors, such as principal, peer, technical, and parental support (Chiu, 2017; Lee et al., 2020). Principal support is among the most important factors, as principals play a crucial role in fostering teachers' motivation (Lee et al., 2020; Shepherd-Jones \& Salisbury-Glennon, 2018). Principal leadership styles are strongly associated with teacher motivation. In a SDTbased study, Shepherd-Jones \& Salisbury-Glennon (2018) found that teachers reported higher levels of autonomy, relatedness, and competence under a principal who was perceived to demonstrate a democratic rather than an authoritarian leadership style. Lee and colleagues (2020) suggested that teachers are more likely to welcome changes and to commit to their jobs when their principals provide learning support (e.g., professional development activities) that satisfies their three basic needs. Leadership is strongly associated with teachers' trust in the school principal, work motivation, and professional learning (Bektaş et al., 2020). Peers (in this context, colleagues) also greatly influence teacher motivation, but few SDT-based studies have analyzed teacher peer support in schools. Among these few studies, Wyatt (2013) suggested that the relationships between colleagues determine the school environment and climate, which can enhance or reduce teachers' sense of relatedness. Carson \& Chase (2009) found that praise from colleagues can enhance teachers' perceived competence and relatedness. Learning support from peers can satisfy the SDT needs, particularly by enhancing competence and relatedness. Thus, technology integration practices can be fostered through the provision of school learning support that satisfies the three SDT needs.

\section{Persistence of teacher technology integration and SDT}

SDT explains the motivational processes that drive persistence and desistance (Ryan \& Deci, 2020). When individuals are autonomously motivated, they have greater cognitive, affective, and energy resources with which to persist (Ryan \& Deci, 2020). The strong association between autonomous motivation and persistence has been extensively demonstrated (Jõesaar et al., 2011; Legault \& Inzlicht, 2013; Moller et al., 2006; Murphy \& Taylor, 2020; Pelletier et al., 2001). For example, autonomous motivation positively predicted engagement in swimming (Pelletier et al., 2001) and sports (Jõesaar et al., 2011) 22 months and 12 months, respectively, after study completion. Learners remain engaged (Moller et al., 2006) and perform better (Legault \& Inzlicht, 2013) for longer when they have chosen the tasks themselves. Individuals with greater perceived autonomy, competence, and relatedness are likely to persist for longer (Milyavskaya \& Koestner, 2011). According to SDT, individuals persist in activities for longer when they more strongly endorse their reasons for engaging in the activities (e.g., they have chosen to do so and engagement feels comfortable and relevant). Such individuals persist in activities because they find them enjoyable, beneficial, and useful. Individuals with low levels of self-endorsement are less likely to persist; they often engage in activities to protect their self-esteem and to avoid feeling guilty (Murphy \& Taylor, 2020). 


\section{Research gaps}

As previously discussed, teacher technology integration research on persistence is needed. Teachers' persistence is strongly associated with their autonomous motivation, as defined by SDT; however, most SDT-based studies have focused on teachers' support and students' motivation and well-being (Chiu, 2021a, b, 2022; Chiu et al., 2021; Ryan \& Deci, 2020). To echo this, literature suggests that more SDT-based studies of teachers' motivations to continue learning (via school learning support) and to achieve their instructional goals (e.g., implementing low- and high- quality integration practices) are necessary Chiu 2021a, b, 2022; Jang, 2019; Jansen, in de Wal et al., 2014; Gorozidis \& Papaioannou 2014). SDT founders Ryan \& Deci (2020) also recently suggested that future studies should include teacher motivation towards the use of technology.

\section{This study}

\section{Research goals}

This study developed a school learning support intervention with three dimensions-leader, expert, and peer support - to satisfy teachers' three basic psychological needs and thereby motivate them to integrate technology in their classrooms.

- Leader learning support: Principals or middle managers (e.g., subject heads) can encourage teachers to choose digital tools that they feel comfortable with and consider suitable by funding their chosen tools and training courses.

- Expert learning support: External bodies such as universities and educational service providers can run professional development workshops for teachers on how to teach with digital tools and offer individual consulting sessions upon teachers' request.

- Peer learning support: Groups (Trio) of learning "buddies" can be formed to provide teachers with mutual support. These groups should hold regular meetings to share their experiences and observe each other's lessons.

This study aimed to investigate how the proposed support encouraged and sustained the low- and high- quality teacher integration practices. The research questions were:

RQ1: What are the perceived needs satisfaction and technology integration quality over the course of the investigation period, in three measurement points, for support and for nonsupport groups?

RQ2: What are the differences between support and non-support groups concerning needs satisfaction and technology integration quality after intervention and 10 months later?

RQ3: How do the teachers see in their views the proposed school learning support?

\section{Research design and procedure}

This study's participants were 122 teachers from two Hong Kong secondary schools in the same district with similar academic performance standards. Sixty-two teachers from one school received the proposed support (SCH_ST) and 60 teachers from the other school 
did not (SCH_NO_ST). In the SCH_ST group, the teachers had an average of 17 years of teaching experience; $65 \%$ of them were female and $35 \%$ were male. In the SCH_NO_ST group, the teachers had an average of 16 years of teaching experience; $67 \%$ were female and $33 \%$ were male. The schools had similar network infrastructures, as each had two computer rooms and fiber-optic connections. The schools had not received any external professional support for technology integration within the two years prior to this study. The author served as the e-learning consultant for both schools.

This experimental and longitudinal study adopted a sequential explanatory mixed-methods design and was conducted over 22 months. A quantitative design was used to compare perceived need satisfaction and the two types of integration practices within and between the schools to answer the first four research questions. The intervention was the proposed school learning support. An online self-reported questionnaire measuring perceived need satisfaction and technology integration practices was administered three times during the study: immediately before and after the intervention and 10 months after the intervention. A qualitative design was used to measure the participants' subjective responses and explain phenomena in the statistical data that could not be described numerically (Fries, 2009). Individual semi-structured interviews were used to collect the teachers' views on how the support motivated them when considering the two types of quality integration practices. Sample questions include "What factors motivate you to use technology to support studentcentered learning/lecturing?"; "How do you feel about the support from your school?"; "What support do you need?"; and "Why do you keep integrating technology in your classrooms in the absence of support?"

The research team included the author, two research assistants, and two experienced school teachers. The author first obtained consent from all of the participants. As their e-learning consultant, the author ran two 3-hour workshops for the two schools' leadership teams, which consisted of their respective principal, vice principals, and subject heads. The workshop topics included formative assessment, blended learning, and collaborative learning. During the first month of the study, at the first staff meeting, two weeks before the school academic year started, all of the teachers completed the online pre-questionnaire. At each school, the principal discussed the school year plan with the teachers. One of the objectives was "using technology to support student-centered learning" (high-quality integration practices). In the SCH_ST group, the school leader team introduced the school support fund to all of the teachers and explained that the teachers could use any available technological tools to support any instructional design they chose. In the SCH_NO_ST group, the school leader team offered no support fund, but instead provided a recommended list of technological tools that the teachers could use (e.g., Kahoot, Google products, and learning management system) to support student-centered learning.

In the second month, the author and the respective leader teams ran four half-day workshops for the teachers in the SCH_ST and SCH_NO_ST groups. The teachers could make appointments for consultations on technology integration with the author and their leader team. From the third through the 12th month of the study, the teachers at both schools shared their experiences within the department. In the SCH_ST group, the teachers chose partners to form trios of learning buddies for mutual support and learning. The buddies met regularly to share their experiences and observe each other's lessons. In the 12th month of the study, all of the participants at both schools completed the mid-questionnaire online. In the SCH_ST group, two teachers from each of six subjects - Chinese, English, Mathemat- 
ics, Sciences, Technology, and Humanities and Art — were randomly selected to participate in 45-minute individual semi-structured interviews. In the 13th to $22 \mathrm{nd}$ months, during the subsequent academic year, the three dimensions of support were not offered to the SCH_ST group. In the 22nd month, all of the participants from both schools completed the post-questionnaire online. The same 12 teachers from the SCH_ST group participated in a second round of 40-minute individual semi-structured interviews.

\section{Instruments}

In addition to collecting demographic data, the questionnaire assessed the two categories of perceived need satisfaction and technology integration practices. The questionnaire included five constructs, each with four 5-point Likert scale items (1: highly disagree/never; 5: highly agree/always). The items were checked by two experienced teachers who were not involved in the main study to ensure that the items were comprehensible.

\section{Basic psychological need satisfaction}

To assess the teachers' need satisfaction, this study used the Basic Psychological Needs Scale-Revised (BPNS-R), which consists of three subscales pertaining to the three SDT needs. The scale was validated across four countries-Belgium, Peru, China, and the United States - by Chen et al., (2015), with a reliability of $\alpha>0.71$, and was further adopted in a related study by Chen, Van Assche, Vansteenkiste, Chen et al., (2015a, b). The participants in these two studies were adults, fitting the research design. This study adapted the three four-item subscales, which included autonomous satisfaction ("I feel a sense of choice and freedom in the things I undertake"; "I feel that my decisions reflect what I really want"; "I feel my choices express who I really am"; "I feel I have been doing what really interests me"), competence satisfaction ("I feel confident that I can do things well"; "I feel capable at what I do"; "I feel competent to achieve my goals"; "I feel I can successfully complete difficult tasks"), and relatedness satisfaction ("I feel that the people I care about also care about me"; "I feel connected with people who care for me, and for whom I care"; "I feel close and connected with other people who are important to me"; "I experience a warm feeling with the people I spend time with"). The questionnaire began with the statement "When integrating technology in classrooms..." to address the research context.

\section{High- and low-quality teacher technology integration practices}

As previously discussed, the quality of teacher technology integration reflects the degree to which teachers use technology to support student-centered learning and to personalize their teaching (Mueller et al., 2008; Vongkulluksn et al., 2018). The teachers' low- and highquality integration practices were assessed according to their teaching and learning activities with technology. This study used four items each to measure the two types of integration practices. The four items for low-quality integration practices were "I use technology to present my teaching content"; "I use technology to collect students' views"; "I use technology to grade quizzes and tests"; and "I use technology to create content for teaching." The four items for high-quality integration practices were "I use technology to provide formative assessment"; "I use technology to help my students to conduct goal setting and self-assess- 
ment"; I use technology to diagnose my students' learning needs"; and "I use technology to foster a collaborative leaning environment for my students."

\section{Research analytic approach}

The data collected from the three questionnaires revealed the changes in the teachers' scores at different stages. To answer RQ1-2, analyses of covariance (ANCOVAs) and t-tests were used to compare the scores between and within the schools. To answer RQ3, the research team used a hybrid inductive and deductive approach and the three needs identified in SDT as a framework to analyze the interview data to understand how the support motivated the two types of integration practices. The research team, guided by the framework, then analyzed the data. First, a research assistant annotated the transcripts with codes. The other research assistant then reviewed all of the annotated transcripts to check the codes and identify any differences in interpretation. The author mediated any such differences. The team then analyzed the codes to understand how the support encouraged the two types of integration practices.

\section{Results}

\section{Descriptive statistics and scale reliability}

Descriptive statistics for all of the variables in the three questionnaires are presented in Table 1. All of the variables were internally reliable, as all of the Cronbach, $\alpha$, values were

Table 1 Descriptive statistics for pre-, post- and delay-questionnaires

\begin{tabular}{|c|c|c|c|c|c|c|c|}
\hline \multirow[b]{2}{*}{ Groups } & \multirow[b]{2}{*}{ Variables } & \multicolumn{2}{|c|}{ Pre-questionnaire } & \multicolumn{2}{|c|}{ Post-questionnaire } & \multicolumn{2}{|c|}{$\begin{array}{l}\text { Delay-ques- } \\
\text { tionnaire }\end{array}$} \\
\hline & & Mean & SD & Mean & SD & Mean & SD \\
\hline \multirow[t]{5}{*}{$\begin{array}{l}\text { SCH_ST } \\
(\mathrm{N}=62)\end{array}$} & $\begin{array}{l}\text { Perceived } \\
\text { autonomy }\end{array}$ & 2.44 & 0.64 & 4.20 & 0.61 & 4.18 & 0.66 \\
\hline & $\begin{array}{l}\text { Perceived } \\
\text { competence }\end{array}$ & 3.00 & 0.88 & 4.30 & 0.80 & 4.27 & 0.78 \\
\hline & $\begin{array}{l}\text { Perceived } \\
\text { relatedness }\end{array}$ & 2.59 & 0.803 & 4.18 & 0.82 & 4.02 & 0.76 \\
\hline & $\begin{array}{l}\text { Low-quality } \\
\text { integration }\end{array}$ & 3.45 & 0.82 & 4.27 & 0.77 & 4.20 & 0.78 \\
\hline & High-quality integration & 2.48 & 0.79 & 4.05 & 0.78 & 3.88 & 0.80 \\
\hline \multirow[t]{5}{*}{$\begin{array}{l}\text { SCH_NO_ST } \\
(\mathrm{N}=60)\end{array}$} & $\begin{array}{l}\text { Perceived } \\
\text { autonomy }\end{array}$ & 2.59 & 0.62 & 2.61 & 0.65 & 2.74 & 0.61 \\
\hline & $\begin{array}{l}\text { Perceived } \\
\text { competence }\end{array}$ & 3.05 & 0.83 & 3.08 & 0.80 & 3.05 & 0.78 \\
\hline & $\begin{array}{l}\text { Perceived } \\
\text { relatedness }\end{array}$ & 2.60 & 0.79 & 2.69 & 0.79 & 2.85 & 0.76 \\
\hline & $\begin{array}{l}\text { Low-quality } \\
\text { integration }\end{array}$ & 3.46 & 0.84 & 4.16 & 0.82 & 3.85 & 1.11 \\
\hline & High-quality integration & 2.44 & 0.76 & 2.96 & 0.80 & 2.40 & 0.76 \\
\hline
\end{tabular}


greater than 0.90 (good > 0.80; Warner 2013) and had sufficiently normal distributions with skewness values below 2.0 and kurtosis of less than 5.0 (Lei \& Lomax, 2005; Bryne, 2010). A one-way analysis of variance revealed no significant differences between the pre-questionnaire scores for perceived autonomy satisfaction, $\mathrm{F}(1,120)=1.79, \mathrm{p}=0.18$; perceived competence satisfaction, $\mathrm{F}(1,120)=0.10, \mathrm{p}=0.75$; perceived relatedness satisfaction, $\mathrm{F}$ $(1,120)=0.002, \mathrm{p}=0.96$; low-quality integration practice, $\mathrm{F}(1,120)=0.005, \mathrm{p}=0.94$; and high-quality integration practice, $F(1,120)=0.07, p=0.79$. These scores indicated that the teachers from the two schools had similar levels of perceived need satisfaction and integration practices before the intervention.

\section{Effects of the school learning support}

To test the effects of the school learning support on perceived need satisfaction and integration practices, ANCOVAs were conducted to compare the scores of the mid-questionnaire while controlling for the pre-questionnaire scores, and paired t-tests were used to examine whether there were increases in the mid-questionnaire scores in each school. Levene's test for homogeneity and normality checks were carried out, and the assumptions were met.

The ANCOVAs, see Table 2, showed that the SCH_ST group $(\mathrm{M}=4.20 ; \mathrm{SD}=0.61)$ perceived significantly higher autonomy than the $\mathrm{SCH}_{-} \mathrm{NO}$ ST group $(\mathrm{M}=2.60 ; \mathrm{SD}=$

Table 2 ANCOVA results of post- and dealy- questionnaires for the two groups

$* \mathrm{p}<.05, * * \mathrm{p}<.01, * * * \mathrm{p}<.001$

\begin{tabular}{|c|c|c|c|c|c|}
\hline \multicolumn{6}{|c|}{ Post-questionnaire (pre-questionnaire as covariate) } \\
\hline Variables & Groups & $\begin{array}{l}\text { Ad- } \\
\text { justed } \\
\text { Mean }\end{array}$ & SE & $\mathrm{F}$ & $\eta^{2}$ \\
\hline \multirow{2}{*}{$\begin{array}{l}\text { Perceived } \\
\text { Autonomy }\end{array}$} & SCH_ST & 4.25 & 0.06 & $443.05 * * *$ & 0.788 \\
\hline & $\mathrm{SCH}$-NO_ST & 2.56 & 0.06 & & \\
\hline \multirow{2}{*}{$\begin{array}{l}\text { Perceived } \\
\text { Competence }\end{array}$} & SCH_ST & 4.31 & 0.07 & $154.40 * * *$ & 0.57 \\
\hline & SCH_NO_ST & 3.01 & 0.07 & & \\
\hline \multirow{2}{*}{$\begin{array}{l}\text { Perceived } \\
\text { Relatedness }\end{array}$} & SCH_ST & 4.18 & 0.07 & $222.16^{* * *}$ & 0.65 \\
\hline & SCH_NO_ST & 2.69 & 0.07 & & \\
\hline \multirow{2}{*}{$\begin{array}{l}\text { Low-quality } \\
\text { Integration }\end{array}$} & SCH_ST & 4.28 & 0.07 & 1.72 & 0.01 \\
\hline & SCH_NO_ST & 4.15 & 0.07 & & \\
\hline \multirow{2}{*}{$\begin{array}{l}\text { High-quality } \\
\text { Integration }\end{array}$} & SCH_ST & 4.04 & 0.08 & $89.88 * * *$ & 0.43 \\
\hline & SCH_NO_ST & 2.98 & 0.08 & & \\
\hline \multicolumn{6}{|c|}{ Delay-questionnaire (post-questionnaire as covariate) } \\
\hline \multirow{2}{*}{$\begin{array}{l}\text { Perceived } \\
\text { Autonomy }\end{array}$} & SCH_ST & 3.66 & 0.08 & $7.35 * *$ & 0.06 \\
\hline & SCH_NO_ST & 3.28 & 0.08 & & \\
\hline \multirow{2}{*}{$\begin{array}{l}\text { Perceived } \\
\text { Competence }\end{array}$} & $\mathrm{SCH}_{-} \mathrm{ST}^{-}$ & 3.78 & 0.06 & $5.07 *$ & 0.04 \\
\hline & SCH_NO_ST & 3.56 & 0.06 & & \\
\hline \multirow{2}{*}{$\begin{array}{l}\text { Perceived } \\
\text { Relatedness }\end{array}$} & SCH_ST & 3.63 & 0.10 & $5.67^{*}$ & 0.05 \\
\hline & SCH_NO_ST & 3.26 & 0.10 & & \\
\hline \multirow{2}{*}{$\begin{array}{l}\text { Low-quality } \\
\text { Integration }\end{array}$} & $\mathrm{SCH}_{-} \mathrm{ST}$ & 4.15 & 0.07 & $5.67^{*}$ & 0.05 \\
\hline & SCH_NO_ST & 3.91 & 0.07 & & \\
\hline \multirow{2}{*}{$\begin{array}{l}\text { High-quality } \\
\text { Integration }\end{array}$} & SCH_ST & 3.52 & 0.08 & $34.76^{* * *}$ & 0.23 \\
\hline & $\mathrm{SCH}$ NO ST & 2.78 & 0.08 & & \\
\hline
\end{tabular}


$0.65), \mathrm{F}(1,119)=443.04, \mathrm{p}<0.001$; the $\mathrm{SCH}$ ST group $(\mathrm{M}=4.30 ; \mathrm{SD}=0.80)$ perceived significantly higher competence than the $\mathrm{SCH}$ _NO_ST group $(\mathrm{M}=3.08 ; \mathrm{SD}=0.80), \mathrm{F}(1$, $119)=154.40, \mathrm{p}<0.001$; and the $\mathrm{SCH}$ ST group $(\mathrm{M}=4.18 ; \mathrm{SD}=0.82)$ perceived significantly higher relatedness than the SCH_NO_ST group $(\mathrm{M}=2.69 ; \mathrm{SD}=0.79), \mathrm{F}(1,119)$ $=221.15, \mathrm{p}<.001$. Regarding integration practices, the analyses showed that the SCH_ST group $(\mathrm{M}=4.27$; $\mathrm{SD}=0.77)$ did not differ significantly from the $\mathrm{SCH}$ _NO_ST group $(\mathrm{M}$ $=4.16 ; \mathrm{SD}=0.82)$ in self-reported scores for low-quality integration practices, $\mathrm{F}(1,119)$ $=1.18, \mathrm{p}=.19$, and the $\mathrm{SCH}$ _ST group $(\mathrm{M}=4.05 ; \mathrm{SD}=0.78)$ reported significantly more high-quality integration practices than the $\mathrm{SCH} \_\mathrm{NO} \_\mathrm{ST}$ group $(\mathrm{M}=2.96$; $\mathrm{SD}=0.80), \mathrm{F}(1$, $119)=89.88, \mathrm{p}<.001$.

The paired t-tests showed that the SCH_ST group had significantly higher scores on the mid-questionnaire than on the pre-questionnaire for perceived autonomy, $t(61)=30.74$, $\mathrm{p}<.001$; perceived competence, $\mathrm{t}(61)=15.90, \mathrm{p}<.001$, perceived relatedness, $\mathrm{t}(61)=$ $21.42, \mathrm{p}<.001$; low-quality integration practices, $\mathrm{t}(61)=12.08, \mathrm{p}<.001$; and high-quality integration practices, $\mathrm{t}(61)=15.52, \mathrm{p}<.001$. The tests also revealed that the SCH_NO_ST group had significantly higher scores on the mid-questionnaire than on the pre-questionnaire scores for the two types of integration practices (low-quality, $\mathrm{t}(59)=9.03, \mathrm{p}<.001$; high-quality, $\mathrm{t}(59)=3.28, \mathrm{p}<.01)$, but there were no significant differences between the pre- and mid-questionnaires in terms of perceived need satisfaction (perceived autonomy, $\mathrm{t}(59)=0.33, \mathrm{p}=.75$; perceived competence, $\mathrm{t}(59)=0.38, \mathrm{p}=.71$; or perceived relatedness, $\mathrm{t}(59)=1.19, \mathrm{p}=.24)$.

\section{Persistence of the school learning support effects}

To examine the persistence of the school learning support effects on perceived need satisfaction and integration practices, ANCOVAs were conducted to compare the post-questionnaire scores by excluding the effects of the mid-questionnaire scores, and paired t-tests were used to examine whether there were increases in the post-questionnaire scores in each school. Levene's test for homogeneity and normality checks were carried out, and the assumptions were met.

For perceived need satisfaction, the analyses, see Table 2, showed that the SCH_ST group $(\mathrm{M}=4.18 ; \mathrm{SD}=0.66)$ perceived significantly higher autonomy than the $\mathrm{SCH} \mathrm{NO}_{-}$ ST group $(\mathrm{M}=2.74 ; \mathrm{SD}=0.61), \mathrm{F}(1,119)=7.35, \mathrm{p}=.01$; the $\mathrm{SCH} S \mathrm{ST}$ group $(\mathrm{M}=4.27$; $\mathrm{SD}=0.78)$ also perceived significantly higher competence than the $\mathrm{SCH}_{-} \mathrm{NO}_{-} \mathrm{ST}$ group $(\mathrm{M}=3.05 ; \mathrm{SD}=0.78), \mathrm{F}(1,119)=5.07, \mathrm{p}=.02$; and the $\mathrm{SCH}$ ST group $(\mathrm{M}=4.02 ; \mathrm{SD}$ $=0.76)$ perceived significantly higher relatedness than the $\mathrm{SCH}$ NO_ST group $(\mathrm{M}=2.85$; $\mathrm{SD}=0.76), \mathrm{F}(1,119)=5.67, \mathrm{p}=.02$. For the integration practices, the analyses further showed that the SCH_ST group $(\mathrm{M}=4.20$; $\mathrm{SD}=0.78)$ reported significantly more lowerquality integration practices than the $\mathrm{SCH}$ NO_ST group $(\mathrm{M}=3.85 ; \mathrm{SD}=1.11), \mathrm{F}(1,119)$ $=5.67, \mathrm{p}=.02$; the $\mathrm{SCH}$ _ST group $(\mathrm{M}=3.88 ; \mathrm{SD}=0.80)$ also reported significantly more high-quality integration practices than the $\mathrm{SCH} \_\mathrm{NO} \_\mathrm{ST}$ group $(\mathrm{M}=2.40 ; \mathrm{SD}=0.76), \mathrm{F}(1$, $119)=34.78, \mathrm{p}<.001$.

The paired t-tests showed that in the SCH_ST group, the post-questionnaire scores were significantly higher than the mid-questionnaire scores for high-quality integration, $\mathrm{t}(61)=$ $2,25, \mathrm{p}<.028$, but not for perceived autonomy, $\mathrm{t}(61)=0.31, \mathrm{p}=.76$; perceived competence, $\mathrm{t}(61)=0.43, \mathrm{p}=.67$; perceived relatedness, $\mathrm{t}(61)=1.81, \mathrm{p}=.08$; or low-quality integration, 
$\mathrm{t}(61)=1.06, \mathrm{p}=.29$. The tests further revealed that in the SCH_NO_ST group, the postquestionnaire scores were significantly lower than the mid-questionnaire scores for the two types of integration practices (low-quality, $\mathrm{t}(59)=4.45, \mathrm{p}<.001$; high-quality, $\mathrm{t}(59)=6.54$, $\mathrm{p}<.01$ ), but there were no differences between the mid- and post-questionnaires for perceived need satisfaction (perceived autonomy, $\mathrm{t}(59)=1.87, \mathrm{p}=.08$; perceived competence, $\mathrm{t}(59)=0.52, \mathrm{p}=.61 ;$ perceived relatedness, $\mathrm{t}(59)=1.67, \mathrm{p}=.10)$.

Overall, the SCH_ST group reported greater perceived need satisfaction and more lowand high-quality integration practices than the SCH_NO_ST group after the intervention. Thus, the intervention increased teachers' perceived need satisfaction and integration practices. The effects of the support persisted in the SCH_ST group but not in the SCH_NO_ST group.

\section{How do the teachers think about the proposed support}

This study used two rounds of semi-structured interviews to collect teachers' views on the proposed support and their persistence in the integration practices. The interview data in the first round concerned how the support satisfied the teachers' needs, and the data from the second round concerned what factors sustained their need satisfaction and integration practices after 10 months.

\section{Perceived autonomy support}

The interview data showed that the school leader team, which included the principal, vice principals, and subject heads, provided the teachers with opportunities to choose their preferred tools and pedagogies for preparing technology-integrated classroom activities. All of the teachers viewed the individual support fund and the absence of designated digital tools as an explicit invitation by school leaders to choose their favorite tools for learning. They felt free, inspired, and encouraged, as shown by the following excerpts.

Teacher 1: The support fund encouraged me to pick and subscribe to two digital tools, and to learn about how to teach with them.

Teacher 2: I felt that my principal endorsed my choice of the digital tool. The tool suits my teaching needs and is one I find useful and easy to use. I should thank my principal.

Teacher 3: No default tool for teaching was a good approach. I can use some familiar tools I have used before.

Teacher 4: I chose these tools because they fit my pedagogy. This is how I teach.

\section{Perceived digital competence support}

The interview data revealed that the professional development activities made the teachers feel more competent in using technology to support student-centered learning. All of the teachers stated that they felt more confident because they had opportunities to consult experts to build up their knowledge, improve their teaching ideas, or have their teaching ideas endorsed. The teachers felt more open and comfortable speaking to someone outside their school and able to share new teaching ideas without being judged or criticized. They believed that the experts, who did not know them, could comment objectively on their ideas, 
and also found the experts' feedback constructive. The following excerpts illustrate how the experts supported teacher learning.

Teacher 5: I felt more comfortable sharing new ideas on instructional designs with the experts. They gave very constructive feedback.

Teacher 6: The individual session with the experts was very useful. They commented objectively on my teaching ideas.

Teacher 7: They [the expert] are outsiders and can give me comments from a new perspective. Their comments were helpful.

Teacher 8: I found the individual meetings very helpful. The experts were open and welcoming. I shared what I wanted to teach with them and received feedback.

\section{Perceived digital relatedness support}

The data also showed that the trios of learning buddies made the teachers feel that they were working together to achieve school objectives and increased their sense of belongingness to their school and learning community. The following are excerpts from the teachers' discussion of how the learning buddies supported relatedness.

Teacher 9: I thought the learning buddies were very good for the new initiatives. We worked as a team, rather than alone.

Teacher 10: I was able to observe other subject teachers' lessons and learn from them how to use technology to support student-centered learning, and the ideas were fresh.

Teacher 11: We have become technology integration buddies.

Teacher 12: I loved this buddy system. I enjoyed it a lot.

\section{Persistence of school learning support effects}

The second-round interview data were used to identify the factors that sustained perceived need satisfaction. The analyses revealed that the three most important factors were (i) comfort with the tools, (ii) benefits of the tools, and (iii) informal learning communities. All of the teachers loved the tools that they used in teaching and wanted to explore new teaching ideas. They also stated that technology increased the effectiveness of student-centered learning. Their groups of learning buddies continued to meet and even grew. The following excerpts illustrate these three factors.

Teacher 1: [The other 11 teachers had similar views.] I found it easy and comfortable to use the tools for teaching. More familiar. I love the tools.

Teacher 2: [The other 11 teachers had similar views.] I can see the benefits of using technology to support student-centered learning. More effective. It saved time and costs when I used technology to teach students (both low-and high-quality).

Teacher 3: [Most teachers had similar views.] I still have my original learning buddies, and now I have more learning buddies. Eight of us learn together and share our experiences. 


\section{Discussions and conclusions}

\section{Empirical implications}

The first empirical implication is that, as predicted, the proposed support significantly satisfied teacher perceived autonomy, competence, and relatedness, resulting in more high-quality technology integration practices. This finding implies that the three support dimensions - leader, expert, and peer - motivated teachers to respond to the school initiative to use technology to support student-centered learning (high-quality). In line with the SDT-based study on teacher work commitment by Lee and colleagues (2020), the findings show that SDT can be used to explain teacher technology integration in classrooms and reveal that promoting autonomy, competence, and relatedness is critical for technology integration. These findings are supported by the interview data. When schools satisfy these three needs, teachers feel a stronger sense of autonomy (choosing technologies for teaching and learning), a stronger sense of competence (using a new pedagogy, student-centered learning), and a stronger sense of relatedness (through connections with their peers for growth). They also align with those of studies suggesting that school support influences the adoption of technology for learning and teaching (Chiu, 2017; Chiu \& Churchill, 2016; Serriawati $\&$ Azwar, 2020). These studies have suggested that insufficient support from schools is a major barrier to the promotion of educational technology initiatives, because without support, teachers tend to have lower self-efficacy and to be less likely to master the skills necessary to pursue the initiatives. Accordingly, effective school learning support should (i) offer support funds that allow teachers to choose their own technological tools, (ii) provide individual consulting sessions to help teachers build the confidence and knowledge needed to pursue initiatives, (iii) provide workshops and talks, and (iv) create learning buddy groups to encourage mutual support and learning. Such support will help to foster teachers' autonomy, competence, and relatedness, in line with findings regarding the application of SDT in the workplace (Lee et al., 2020).

Second, for low-quality integration, the teachers in both groups used technology to support student-centered learning, and the difference between the groups was not significant. These results suggest that teachers may not need school learning support for low-quality integration practices. It is because teachers practiced low-quality technology integration to save time and costs (Cheng et al., 2020). Low-quality integration practices are less complex and cognitively demanding than high-quality practices, and that they are a prerequisite for high-quality practices (Chiu et al., 2020). The teachers found it easy to implement lowquality practices to work toward school-based initiatives and policies.

The final empirical implication is that the teachers who received the school learning support derived from SDT were significantly more persistent in need satisfaction and quality integration practices than the teachers who did not receive the support. These results align with those of prior SDT studies (Lee et al., 2020; Murphy \& Taylor, 2020). Persistent teachers are likely to have greater perceived autonomy, competence, and relatedness (Milyavskaya \& Koestner, 2011). Persistence in integration practices should be greater when teachers have higher self-endorsement of their engagement in these (comfort in RQ3) and other practices (informal learning communities in RQ3); in this case, the proposed school support. The teachers' high engagement indicated high self-endorsement because they found the practices fun and beneficial (benefits in RQ3), and they were more persistent than 
teachers who engaged for reasons indicative of low endorsement, such as protecting their self-esteem and avoiding feeling guilty (Lee et al., 2020; Murphy \& Taylor, 2020). Autonomously motivated teachers have more to gain from being persistent and are better able to recruit the necessary cognitive, affective, and energetic resources to persist (e.g., informal learning communities in Ryan \& Deci 2020). This autonomous motivation is like an energy source that encourages the teachers to engage behaviorally, cognitively, and emotionally in using technology to support student-centered learning (Reeve, 2013).

\section{Theoretical contributions}

The first and second empirical implications contribute to SDT by indicating that the effectiveness of needs-based support is affected by the complexity of the activities and tasks involved. The proposed school learning support motivated the teachers to engage in more high-quality technology integration practices, which are relatively complex, but not lowquality practices. This implies that in the work environment, individuals commit to activities that they feel capable of doing under external expectations or pressure. The related needs-based support may not be effective for less complex jobs and tasks. The majority of SDT-based studies of support for employee needs have considered how school support relates to work engagement, commitment, and well-being (Lee et al., 2020). However, few SDT-based studies have examined which activities require support and when. Therefore, this study suggests that the application of SDT should take task complexity into account.

The second theoretical contribution, which is driven by the third empirical implication, concerns the after-effects of needs-based support. In this study, low-quality integration practices, which were not motivated by the proposed school learning support, were sustained for 10 months. This implies that the support may have affected persistence even though it did not directly affect engagement. Accordingly, this study posits that activity complexity may determine the effects (either immediate or delayed) of needs-based support.

\section{Practical suggestions}

Studies on teacher development programs for technology integration have focused on the introduction of new digital tools, the development of digital skills, technological skills, and curriculum design, and the sharing of experiences (Chiu, 2017; Chiu \& Churchill, 2016). These programs can prepare and motivate teachers to use technology in learning and teaching by enhancing their self-efficacy and increasing the perceived ease of use and usefulness of the technology, and by introducing innovative instructional strategies. This study is aligned with the current research and advocacy from COVID-19 (e.g., teacher wellbeing; Chiu et al., 2021), and offers a different approach to supporting teacher technology integration practices that emphasizes teacher motivation, persistence, and well-being.

Three practical suggestions are thus offered for school leaders, teacher educators, and policy makers to satisfy teachers' basic needs and thereby increase their engagement in technology integration practices. The first is to promote autonomy by offering support funds for teacher learning. Teachers should use the funds to attend workshops on the tools of their choice. Accordingly, teachers can directly benefit from the autonomy provided by the 
fund. The second suggestion is that schools work with external bodies such as universities, academic associations, and educational technology service providers to offer workshops and individual consultant sessions to teachers. As performance reviewers, school leaders may elicit stress and doubt in teachers when they ask for advice. Teachers may consider what they share to be part of their performance evaluation. This suggestion is thus to protect teachers' self-esteem and enhance their confidence and self-efficacy (Sahin, 2017). Teachers are more likely to be receptive to competence-based feedback from external bodies. The third suggestion is to encourage teachers to form their own informal learning communities by offering incentives (Judge \& O'Bannon, 2008). In schools, teachers are often grouped according to their subjects and functional groups; therefore, such communities should be formed voluntarily, and should not be limited to teachers' own subjects or working units. Schools should reduce teaching loads or offer bonuses for any communities formed. The final suggestion is that schools should use strategic planning to allocate their resources for needs-based support. They should offer greater support for more difficult or challenging tasks to avoid wasted resources, as needs-based support may not be effective for simple tasks.

\section{Limitations and future research directions}

Three limitations of this study are noted. First, the finding that the three support dimensions can increase teacher engagement in quality integration practices is based on self-reported data. Additional studies using objective measures (McIntyre et al., 2016), such as the frequency and duration of practices or students' perceptions, are needed to validate the findings. Second, this study did not analyze how the different types of motivation related to the teachers' integration practices or discuss the SDT framework comprehensively (Ryan \& Deci, 2020). Future studies should investigate the roles of different types of motivation in integration practices. Finally, this study found strong associations between school support and technology integration. Future studies should use structural equation modeling to examine how needs-based support and teacher motivation affect technology integration (Cheng et al., 2020; Lee et al., 2020).

\section{Compliance with ethical standards}

- This study had got the ethical approval from the Survey and Behavioural Research Ethics Committee in the Chinese University of Hong Kong before the data is collected.

- There is no conflict of interests between the author and participants.

- The author got consents from all the participants.

\section{References}

Bektaş, F., Kılınç, A., \& Gümüş, S. (2020). The effects of distributed leadership on teacher professional learning: mediating roles of teacher trust in principal and teacher motivation. Educational Studies, Advance online publication, 1-23. https://doi.org/10.1080/03055698.2020.1793301

Bryne, B. M. (2010). Structural equation modeling with MPlus (1st ed.). Routledge 
Carson, R. L., \& Chase, M. A. (2009). An examination of physical education teacher motivation from a selfdetermination theoretical framework. Physical Education and Sport Pedagogy, 14(4), 335-353. https:// doi.org/10.1080/17408980802301866

Chen, B., Van Assche, J., Vansteenkiste, M., Soenens, B., \& Beyers, W. (2015a). Does psychological need satisfaction matter when environmental or financial safety are at risk? Journal of Happiness Studies, $16,745-766$

Chen, B., Vansteenkiste, M., Beyers, W., Boone, L., Deci, E. L., Van der Kaap-Deeder, J. \& Verstuyf, J. (2015b). Basic psychological need satisfaction, need frustration, and need strength across four cultures. Motivation and Emotion, 39, 216-236. https://doi.org/10.1007/s10902-014-9532-5

Cheng, S. L., Lu, L., Xie, K., \& Vongkulluksn, V. W. (2020). Understanding teacher technology integration from expectancy-value perspectives. Teaching and Teacher Education, 91, 103062. https://doi. org/10.1016/j.tate. 2020.103062

Chiu, T. K. F. (2022). Applying the Self-determination Theory (SDT) to explain student engagement in online learning during the COVID-19 pandemic. Journal of Research on Technology in Education, 54(sup1), 14-30. https://doi.org/10.1080/15391523.2021.1891998

Chiu, T. K. F. (2021a). Digital support for student engagement in blended learning based on Self-determination Theory. Computers in Human Behavior, 124, 106909 https://doi.org/10.1016/j.chb.2021.106909

Chiu, T. K. F. (2021b). Student engagement in K-12 online learning amid COVID-19: A qualitative approach from a self-determination theory perspective. Interactive Learning Environments. Advanced online publication. https://doi.org/10.1080/10494820.2021.1926289

Chiu, T. K. F. (2017). Introducing electronic textbooks as daily-use technology in schools: A top-down adoption process. British Journal of Educational Technology, 48(2), 524-537. https://doi.org/10.1111/ bjet. 12432

Chiu, T. K. F., Lin, T. J., \& Lonka, K. (2021). Motivating online learning: The challenges of COVID-19 and beyond. Editorials. The Asia-Pacific Education Researcher, 30, 187-190. https://doi.org/10.1007/ s40299-021-00566-w

Chiu, T. K. F., Jong, M. S. Y., \& Mok, I. A. C. (2020). Does learner expertise matter when designing emotional multimedia for learners of primary school mathematics? Educational Technology Research and Development, 68, 2305-2320. https://doi.org/10.1007/s11423-020-09775-4

Chiu, T. K. F., \& Churchill, D. (2016). Adoption of mobile devices in teaching: Changes in teacher beliefs, attitudes and anxiety. Interactive Learning Environments, 24(2), 317-327. https://doi.org/10.1080/104 94820.2015.1113709

Deci, E. L., \& Ryan, R. M. (1985). Intrinsic motivation and self-determination in human behavior. New York: Plenum Press

Ertmer, P. A. (1999). Addressing first-and second-order barriers to change: Strategies for technology integration. Educational Technology Research and Development, 47(4), 47-61. https://doi.org/10.1007/ BF02299597

Fathali, S., \& Okada, T. (2018). Technology acceptance model in technology-enhanced OCLL contexts: A self-determination theory approach. Australasian Journal of Educational Technology, 34(4) 138-154, https://doi.org/10.14742/ajet.3629

Fries, C. J. (2009). Bourdieu's reflexive sociology as a theoretical basis for mixed methods research: An application to complementary and alternative medicine. Journal of Mixed Methods Research, 3(4), 326-348. https://doi.org/10.1177/1558689809336660

Gorozidis, G., \& Papaioannou, A. G. (2014). Teachers' motivation to participate in training and to implement innovations. Teaching and Teacher Education, 39, 1-11. https://doi.org/10.1016/j.tate.2013.12.001

Hur, J. W., Shannon, D., \& Wolf, S. (2016). An investigation of relationships between internal and external factors affecting technology integration in classrooms. Journal of Digital Learning in Teacher Education, 32(3), 105-114. https://doi.org/10.1080/21532974.2016.1169959

Heck, R. H., \& Hallinger, P. (2014). Modeling the longitudinal effects of school leadership on teaching and learning. Journal of Educational Administration, 52(5), 653-681. https://doi.org/10.1108/ JEA-08-2013-0097

Hsu, P. S. (2016). Examining current beliefs, practices and barriers about technology integration: A case study. TechTrends, 60(1), 30-40. https://doi.org/10.1007/s11528-015-0014-3

Inan, F. A., \& Lowther, D. L. (2010). Factors affecting technology integration in K-12 classrooms: A path model. Educational technology research and development, 58(2), 137-154. https://doi.org/10.1007/ s11423-009-9132-y

Jang, H. R. (2019). Teachers' intrinsic vs. extrinsic instructional goals predict their classroom motivating styles. Learning and Instruction, 60, 286-300. https://doi.org/10.1016/j.learninstruc.2017.11.001

Jansen in de Wal, den Brok, P. J., Hooijer, J. G., Martens, R. L., \& van den Beemt, A. (2014). Teachers' engagement in professional learning: Exploring motivational profiles. Learning and Individual Differences, 36, 27-36. https://doi.org/10.1016/j.lindif.2014.08.001 
Jõesaar, H., Hein, V., \& Hagger, M. S. (2011). Peer influence on young athletes' need satisfaction, intrinsic motivation and persistence in sport: A 12-month prospective study. Psychology of Sport and Exercise, 12(5), 500-508. https://doi.org/10.1016/j.psychsport.2011.04.005

Judge, S., \& O'Bannon, B. (2008). Faculty integration of technology in teacher preparation: Outcomes of a development model. Technology, Pedagogy and Education, 17(1), 17-28. https://doi. org/10.1080/14759390701847435

Lee, E., \& Hannafin, M. J. (2016). A design framework for enhancing engagement in student-centered learning: Own it, learn it, and share it. Educational Technology Research and Development, 64(4), 707-734. https://doi.org/10.1007/s11423-015-9422-5

Lee, A. N., \& Nie, Y. (2014). Understanding teacher empowerment: Teachers' perceptions of principal's and immediate supervisor's empowering behaviours, psychological empowerment and work-related outcomes. Teaching and teacher education, 41, 67-79. https://doi.org/10.1016/j.tate.2014.03.006

Lee, A. N., Nie, Y., \& Bai, B. (2020). Perceived principal's learning support and its relationships with psychological needs satisfaction, organisational commitment and change-oriented work behaviour: A Self-Determination Theory's perspective. Teaching and Teacher Education, 93, 103076. https://oi. org/10.1016/j.tate.2020.103076

Legault, L., \& Inzlicht, M. (2013). Self-determination, self-regulation, and the brain: Autonomy improves performance by enhancing neuroaffective responsiveness to self-regulation failure. Journal of Personality and Social Psychology, 105(1), 123. https://doi.org/10.1037/a0030426

Lei, M., \& Lomax, R. G. (2005). The effect of varying degrees of nonnormality in structural equation modeling. Structural equation modeling, 12(1), 1-27. https://doi.org/10.1207/s15328007sem1201_1

Lowther, D. L., Inan, F. A., Strahl, D., J., \& Ross, S. M. (2008). Does technology integration "work" when key barriers are removed? Educational Media International, 45(3), 195-213. https://doi. org/10.1080/09523980802284317

McIntyre, T. M., McIntyre, S. E., Barr, C. D., Woodward, P. S., Francis, D. J., Durand, A. C. \& Kamarck, T. W. (2016). Longitudinal study of the feasibility of using ecological momentary assessment to study teacher stress: Objective and self-reported measures. Journal of Occupational Health Psychology, 21(4), 403. https://doi.org/10.1037/a0039966

Milyavskaya, M., \& Koestner, R. (2011). Psychological needs, motivation, and well-being: A test of selfdetermination theory across multiple domains. Personality and Individual Differences, 50(3), 387-391. https://doi.org/10.1016/j.paid.2010.10.029

Moersch, C. (1995). Levels of technology implementation (LoTi): A framework for measuring classroom technology use. Learning and Leading with Technology, 23, 40-40. https://eric.ed.gov/?id=EJ515029

Moller, A. C., Deci, E. L., \& Ryan, R. M. (2006). Choice and ego-depletion: The moderating role of autonomy. Personality and Social Psychology Bulletin, 32(8), 1024-1036. https://oi. org/10.1080/09523980802284317

Mueller, J., Wood, E., Willoughby, T., Ross, C., \& Specht, J. (2008). Identifying discriminating variables between teachers who fully integrate computers and teachers with limited integration. Computers \& Education, 51(4), 1523-1537. https://doi.org/10.1016/j.compedu.2008.02.003

Murphy, S. L., \& Taylor, I. M. (2020). Priming autonomous and controlling motivation and effects on persistence. Current Psychology, Advanced online publication, 1-13. https://doi.org/10.1007/ s12144-020-00921-y

Nelson, M. J., Voithofer, R., \& Cheng, S. L. (2019). Mediating factors that influence the technology integration practices of teacher educators. Computers \& Education, 128, 330-344. https://doi.org/10.1016/j. compedu.2018.09.023

Nie, Y., Chua, B. L., Yeung, A. S., Ryan, R. M., \& Chan, W. Y. (2015). The importance of autonomy support and the mediating role of work motivation for well-being: Testing self-determination theory in a Chinese work organisation. International Journal of Psychology, 50(4), 245-255. https://doi.org/10.1002/ ijop. 12110

Pelletier, L. G., Fortier, M. S., Vallerand, R. J., \& Briere, N. M. (2001). Associations among perceived autonomy support, forms of self-regulation, and persistence: A prospective study. Motivation and Motion, 25(4), 279-306. https://doi.org/10.1023/A:1014805132406

Richardson, P. W., \& Watt, H. M. (2018). Teacher professional identity and career motivation: A lifespan perspective. In P. A. Schutz, J., Hong \& D. C. Francis (Eds.), Research on teacher identity (pp. 37-48). Cham: Springer. https://doi.org/10.1007/978-3-319-93836-3_4

Reeve, J. (2013). How students create motivationally supportive learning environments for themselves: the concept of agentic engagement. Journal of Educational Psychology, 105, 579-595. https://doi. org/10.1037/a0032690

Ryan, R. M., \& Deci, E. L. (2020). Intrinsic and extrinsic motivation from a self-determination theory perspective. Definitions, theory, practices, and future directions. Contemporary Educational Psychology, 61, 101860. https://doi.org/10.1016/j.cedpsych.2020.101860 
Sahin, H. (2017). Emotional Intelligence and Self-Esteem as Predictors of Teacher Self-Efficacy. Educational Research and Reviews, 12(22), 1107-1111. https://doi.org/10.5897/ERR2017.3385

Serriawati, M., \& Azwar, S. (2020). Correlation between perceptions of school support and the mastery of information technology to teachers' self-efficacy. Journal of Psychology and Instruction, 4(1), 22-28. https://ejournal.undiksha.ac.id/index.php/JoPaI

Shepherd-Jones, A. R., \& Salisbury-Glennon, J. D. (2018). Perceptions Matter: The Correlation between Teacher Motivation and Principal Leadership Styles. Journal of Research in Education, 28(2), 93-131. https://files.eric.ed.gov/fulltext/EJ1201598.pdf

Teo, T., Lee, C. B., Chai, C. S., \& Choy, D. (2009). Modelling pre-service teachers' perceived usefulness of an ICT-based student-centred learning (SCL) curriculum: A Singapore study. Asia Pacific Education Review, 10(4), 535-545. https://doi.org/10.1007/s12564-009-9051-y

Vongkulluksn, V. W., Xie, K., \& Bowman, M. A. (2018). The role of value on teachers' internalization of external barriers and externalization of personal beliefs for classroom technology integration. Computers \& Education, 118, 70-81. https://doi.org/10.1016/j.compedu.2017.11.009

Warner, R. M. (2013). Applied statistics: From bivariate through multivariate techniques (2nd ed.). Los Angeles, CA: Sage

Wyatt, M. (2013). Motivating teachers in the developing world: Insights from research with English language teachers in Oman. International Review of Education, 59(2), 217-242. https://doi.org/10.1007/ s11159-013-9358-0

Publisher's Note Springer Nature remains neutral with regard to jurisdictional claims in published maps and institutional affiliations.

Thomas K.F. Chiu is an assistant professor in the Department of Curriculum and Instruction at the Faculty of Education at The Chinese University of Hong Kong. His research interests include Digital Education, STEM education, and Teacher Education. 